\title{
Statement on reduced risk is misleading
}

\author{
Graeme D Ruxton professor \\ University of St Andrews, St Andrews KY14 8TS, UK
}

O'Neill makes a plausible case for rethinking attitudes to older drivers. ${ }^{1}$ However, his description of key current literature- - "the risk of serious injury to children is halved if driven by grandparents rather than parents"-is misleading. ${ }^{2}$

Unless they read the source paper, readers would not realise that the risk referred to is contingent on being in a car crash. It is not the risk per journey or per distance travelled, but it is a measure only of the consequences if a crash occurs. This is summed up in the final sentences of the source paper. "Finally, our study does not include information about non-crash exposure to vehicle travel. Therefore we cannot estimate the overall risk of crash occurrence or child injury for grandparent versus parent driven child passengers; rather, we can only compare this risk of injury for those child passengers involved in crashes."

Competing interests: None declared.

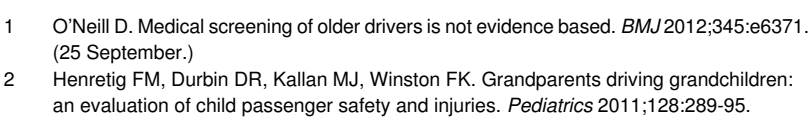

2 Henretig FM, Durbin DR, Kallan MJ, Winston FK. Grandparents driving grandchildren: an evaluation of child passenger safety and injuries. Pediatrics 2011;128:289-95.

Cite this as: BMJ 2012;345:e7060

๑) BMJ Publishing Group Ltd 2012 